\title{
Building trust in e-banking and its effect on positive word-of-mouth advertising
}

\author{
Ali Shaemi ${ }^{\mathrm{a}}$ and Zahra Saneian ${ }^{\mathrm{b}^{*}}$ \\ ${ }^{a}$ Assistant professor and member of scientific board of management team, University of Isfahan, Iran \\ ${ }^{b}$ Master of business administration, University of Isfahan, Iran \\ CHRON I C L E \\ Article history: \\ Received 5 January 2014 \\ Received in revised format \\ 8 March 2014 \\ Accepted 16 March 2014 \\ Available online \\ 18 March 2014 \\ Keywords: \\ Electronic commerce \\ Electronic banking \\ Electronic trust \\ Word of mouth advertising

\section{A B S T R A C T} \\ Nowadays, new technologies have changed the way of serving customers in many service \\ organizations including banking industry. The importance of websites and their exclusive \\ characteristics in presenting various kinds of services to the bank customers has increased. This \\ paper presents a compound model to investigate the effect of traditional and online elements on \\ customers' trust in electronic banking and word of mouth advertisement. For this purpose, a \\ standard questionnaire based on Likert segmentation has been used and 384 customers of \\ Shiraz Mellat bank branches have been tested, randomly. Using structural equation modeling, \\ the study shows that both traditional characteristics of bank and website characteristics rather \\ have positive effects on customers' trust in electronic banking, which increase word of mouth \\ advertising, positively.
}

\section{Introduction}

Remarkable progress in information and transmission technology in recent decades has made significant changes on all human's characteristics and many have attempted to take advantages of new concepts such as electronic government, electronic commerce, electronic banking, electronic insurance, electronic management and electronic learning (Goodarzi \& Zobeydi, 2008). Characteristics such as cost reduction, income increase and customer satisfaction have motivated many organizations to benefit from competitive advantage resulted from electronic commerce. Since one of fundamental basis of electronic commerce development is associated with financial electronic transactions and doing these kinds of activities are possible through bank networks; so having update electronic banking system plays essential role on e-banking. In fact, electronic banking is considered as an inseparable part of electronic commerce and it plays key role on its performance and development (Fakut Saqieh, 2009). Online banking usually is known as network banking or electronic banking and it has experienced a wonderful growth in recent years. The growth speed in

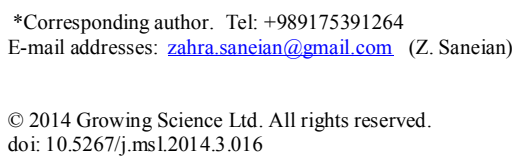


electronic banking is not the same as using internet and this gap has been associated with the lack of trust among bank customers especially among internet users who are 65 years old and older (Yap et al., 2010). Researchers have reported that while trust in traditional concept concentrates on trust in commercial partner but trust in electronic commerce includes trust concept in thematic control (technology trust) substructures and mechanism associated with trade truthfulness, authenticity, being secret and non-repudiation (McCole et al., 2010). If the customers do not trust, their personal information is kept privately, payments are executed securely and only with appropriate permission, they will not use internet. Concerns about privacy in internet and trust are inseparably connected and may have impact on online shopping intension (Liao et al., 2011). It is important to lead customers to do online banking for cost reduction and helping banking economy (Hoehle et al., 2012). The lack of trust can be resolved by a better comprehension of elements improving customers trust in electronic banking. Understanding this issue that the trust should be improved is important for managers and they can create this development and improvement by a combination of traditional and online instruments. However, banks increasingly encounter with a conceptive architecture: the customers may admire electronic banking very easily but since they are separated from traditional banking, the range and the amount of interpersonal interactions with personnel and also transmission cost and finally customer's long-term commitment will also decrease. This question still exists just because bank managers see the traditional and online banking mutually exclusive or changeable. This view is also observable in academic research in this domain because many researchers who performed an investigation on the issue of trust in banking part limited their studies only to structures associated with potential characteristics or only to the internet (Yap et al., 2010).

\section{Theoretical basis and research history}

\subsection{Electronic banking}

One of essential instruments for realization and development of electronic commerce is existence of electronic banking system, which operates along with monetary and financial world system and facilitates activities associated with electronic commerce. In fact, performing electronic commerce requires realization of electronic banking. Because of this purpose, using electronic systems in financial and credit organizations is becoming more popular (Pour Zarandi \& Najafi, 2012). Electronic banking is modern method of banking where information, transmission technologies are applied and paying and transferring mechanism is accomplished electronically (Liao \& Tow Chung, 2001).

\subsection{Electronic trust}

Both university and economy equally describe trust as a central factor helping boost of electronic commerce. Rousseau et al. (1998) described trust as "a mental state including tendency to accept of damage based on positive expectations of opponent tendencies and behavior". Trust can decrease unreliability caused by other people, objects and therefore, it is essential for commerce. It also has an impact on customers' fear of risk and unreliability. In electronic commerce where there is only source of information for overcoming website unreliability, trust in website maintains the highest importance because it is one of the most effective ways for decreasing customers' unreliability. Especially, trust in online environment is important because of variety and complication of online transactions and unreliability and unpredictable behaviors. Therefore, the consumers should be sure about seller not abusing and actions like unfair pricing, breach of privacy and security and presenting wrong information (Weisberg et al., 2011). The concept of trust has been examined in various fields during years. Researchers in various fields agree on the relative importance of trust in doing human jobs but it seems that there was a wide lack of agreement on an appropriate description. Trust has been described in different forms, including: tendency to vulnerability in opponent activities (Mayer et al., 1995), the likelihood that a person connects to cooperating behavior by opponents (Hwang \& Burgers, 1997), a person's believes in the other person that the opponent will behave predictable 
(Luhmann, 1979). Many people believe that trust is in agreement with the perception of risk. In a wider concept, trust is a psychological phrase, which includes tendency to accept damage based on positive expectations of objectives or other's behavior (Midha, 2012). According to Melao (1964), trust is a key member in appearing and keeping social trade relationships. Bradach and Eccles (1989) considered trust as a control mechanism, which facilitates trade relations with the characteristics like uncertainty, vulnerability and dependency. Customers normally look for decreasing unreliability and online trades' complications by using mental shortcuts. Trust is one of these effective mental shortcuts, which can act as a mechanism to decrease human behavior complications under some special circumstances that people have to cope with unreliability. Since the key of successful economic trades is to avoid opportunistic behaviors, online customers generally avoid online sellers in which they do not trust or known as bad (Fang et al., 2011). Ratnasingham (1999) suggested trust technology term and defined aspects of security services like secret mechanisms, identification confirm mechanism, and access to control mechanisms, which leads to increase of technology trust in an empowerment process for supporting privacy, accuracy, correctness, authorized trustee, answering electronic trade transactions (Granber-Krauter \& Faullant, 2008). Therefore, important precursors for continuity of trade relationships are customers' beliefs and tendencies associated with trust in seller's website. Such beliefs depend on risk level perceived by customer and their perceived control level of information that web seller has to exchange (Palvia, 2009).

\section{Developing hypothesis and research conceptive pattern}

\subsection{Traditional characteristics of bank}

Trust in electronic banking comes from structural reliance that a customer understands from size and reputation of a bank. Size of an organization is often considered as a symbol of safety and reliability. Doney and Cannon (1997) and Jarvenpaa et al. (2000) stated that if a company is big enough, it may do good for growing and reaching to this size. In online environment with no physical clues by the help of which the customer can figure the trust, the size of the company is the rescue way in which the customer can make choice in trust in firm in electronic commerce environment. A customer should be able to believe that the seller has the ability of delivering product or services and the size of the company is one of the points and bank reputation shows its reliability and in many real-world cases (Yap et al., 2009).

\subsection{Trust in electronic banking}

McKnight and Chervany (2002) presented a kind of trust in term of electronic commerce including occasional trust and institutional trust and interpersonal trust. The one, which has a high association with this research, is institutional trust, which can be defined as "a personal belief that present desirable situation leads to success situation". The institutional trust also comes from two parts of situational norms and structural reliance (Yap et al., 2009).

\subsubsection{Situational norms}

McKnight et al. (1998) described situational norms as "believe that there is probability for success because the situation and occasion is normal". In addition, McKnight et al. $(1998,2002)$ claimed that norms perception increases matching and comfort of consumers with an online environment. The customers understand situational norms clues from website characteristics (Yap et al., 2009; Eastelik \& Lotz, 2010).

\subsubsection{Structural assurance}

Structural assurance means that there were legal and technological structures to guarantee payment security (Zhou, 2011). Institutional based structural reliance influences initial intentions and beliefs 
positively and privacy concerns negatively. In addition, in order to present guarantees, legal referral options and word of mouth advertisement, researchers state that establishing safety for personal information is an important structural reliance. Protecting privacy and security policies leads to stronger trust beliefs (Eastelik \& Lotz, 2010).

\subsection{Website characteristics}

\subsubsection{Perceived privacy}

Perceived privacy is the probability that online companies gather information about people and use them, inappropriately. There are growing concerns about safety issues and using information online in association with protecting privacy of personal information and unintended use of them. The customers do not tend to enter their information when the website asks them because they are worry about tracking and abusing their sent information on the internet and how they are used. Therefore, online consumers are hesitant to online companies for disclosure of their financial and personal information because they feel that the company has abused them or they will be available for other organizations (Roca et al., 2008).

\subsubsection{Perceived security}

Since financial and personal information can be pursued and used with the object of forge, online investigation is involved with more security concerns than ordinary trades. While making financial trades, one needs to feel safe and this is still one of the primary obstacles in electronic trade growth. Perceived security is described as a threat that causes situations, condition or occurrence with the potential of creating economic problem for network sources data in form of destruction, unfolding, data reformation, service deprivation or forging, wastage and misuse. The safety that includes technical developments like pictography, digital signature and certifications with the goal of protecting users against forging and hacking risks, influences positively on online shopping intention. However, what is associated with acceptance of electronic commerce, is not objective security of electronic channels as a transaction media rather consumers subjective perception of risk. Therefore, when online sellers perform safety mechanism, customers intend to believe that online shopping is safe (Roca et al., 2008). Nevertheless, consumers' comprehension of online safety is totally a different subject and at present time, a few investigations about this subject have been done. Inferences a safety concerns by electronic system users at first were surveyed in information system researches especially on organization systems setting. Regarding to safety concerns of online consumers, recent investigations referred that consumers comprehension about unfavorable safety in internet would continue even until sellers use safety making mechanisms (Chellappa, 2013).

\subsubsection{Perceived ease of use}

Perceived ease of use refers to users' evaluation to the extent that a special system in comprehension, learning and operating will not need physical and mental effort. While the perceived usefulness of using a system, perceived ease of use are associated with inner motivation along with experiencing undesirable system, which facilitate obtaining desirable result (Çelik, 2011). The facility of searching in websites is a key to improve online trust, in the other words, users can simply find the information they look for on the websites. The studies have shown that the ease of use influences on online trust, for example facility in search, transactions, broken links and location finding are totally related to changes in online trust (Kamari \& Kamari, 2012).

\subsection{Tendency to matching with electronic banking}

Absence of trust prevents the consumer to involve in online trade. On the contrary, trust creates a positive attitude toward online retailer and decreases the fear of using system online. A high level of 
trust like a belief and special opinion to the other side of the trade is associated with tendency in high use. In general, trust is an important element for predicting cooperation in trades' relations and trust can be an important pioneer element for predicting online cooperation (Kim \& Song, 2010). In the situation that risk, unreliability and dependencies exist, trust is essential and critical and online environment certainly has these factors with it. Increasing trust means, that person's attitude about a special behavior (in this case, using electronic banking) is positive and probably increases the person's tendency in forming that behavior. Jarvenpaa et al. (2005) found that this subject about electronic banking is true (Yap et al, 2010).

\subsection{Word of mouth advertisement}

The literature state that word of mouth advertisement is considered as a strong tool for marketing and the marketers noticed the importance of word of mouth advertisement especially regarding to its applications for trust and its related results. Some people defined word of mouth advertisement as the relation among consumers about a product, service or a company where sources are considered independent from commercial influence (Sotriadis \& Zyl, 2013). Word of mouth advertisement is defined as a direct exchange of oral messages or connections between a source and a receiver. In this form of interpersonal exchange, the transmitter often is described as the one stating its oral experiences that when they are positive they are enjoyable and when they are negative they are stigmatic. Although it is very likely that a person advise a service organization after a positive experience, word of mouth advertisement also operates as a mechanism for decreasing transmitter's cognitive imbalance or negative experience after shop. Studies show that for the receiver, word of mouth advertisement has an important role during the process of evaluating consumer by turning to a key factor to help decreasing different risks like mental, financial, temporal and social, as it increases receiver perception, positively about a service organization. In general, interpersonal communications have strong impact on decision of service purchasing and act as an advertisement attraction, which leads to increase of profitability and reinforcement of the brand illustration presenting service. Some people reported that word of mouth communications depend on other service organization change before making choice. Yet most of service marketing researches have focused on consumers' verbal communication generation; often emphasize canonical theories and structures like service quality and satisfaction as separate or independent pre structures effective on consumers' tendency to involve in word of mouth advertisement behavior (Chang et al., 2013). It is certainly obvious that final profit of transmitter of word of mouth advertisement is satisfaction of personal needs. Yet for satisfying these needs through word of mouth advertisement, a person needs to involve in a social interaction, which needs social considerations. Social interaction process needs to compare itself with others and prepares sense of need to attachment for creating social relation. Satisfying social needs is also a profit for word of mouth transmitter (Alexandra et al., 2013).

Yap et al. (2010) surveyed online and offline banking in a same research. Their statistical society was ten universities and administrative staff who had more chance in accurate and trustworthy answering to the questions. They concluded that traditional services quality could cause customer's trust in electronic banking services. The range and reputation of the bank make structural guarantee for customer but not in absence of traditional services quality.

Chung and Shin (2010) tried to highlight the importance of relation utility elements (client's satisfaction, trust and electronic commitment) on positive word of mouth advertisements in online retails. The results showed that all of the website characteristics had positive effect on client's satisfaction. 


\section{The proposed study}

Hypothesis 1: Electronic banking website characteristics influences on customer's trust in electronic banking.

Hypothesis 1-a: The perceived ease of using website influences on electronic banking.

Hypothesis 1-b: Customer's perceived privacy of bank website influences on customer's trust in electronic banking.

Hypothesis 1-c: Customer's perceived security of bank website influences on customer's trust in electronic banking.

Hypothesis 2: Bank traditional characteristics influence on customer's trust in electronic banking.

Hypothesis 2-a: Perceived size of bank influences on customer's trust in electronic banking.

Hypothesis 2-b: Perceived reputation of bank influences on customer's trust in electronic banking.

Hypothesis 3: Trust in electronic banking influences on customer's intention to matching with electronic banking.

Hypothesis 4: Intention to matching with electronic banking influences on word of mouth advertisements.

\section{Methodology}

Research Statistic society includes all customers of Shiraz Mellat bank branches. The proposed study selects 384 regular customers of Mellat bank branches, randomly and it has adopted a standard questionnaire originally developed by Yap et al. (2009) and Molinari et al. (2008). Amos software has been applied for scoring Likert interval scale questionnaire and in order to analysis of research data. Narrative and formal term is related to a level of rationality of a test in the view of those who reply it. For this purpose, the questionnaire was given to 5 people of pundits and professors including faculty advisor and supervisors and they were asked about each question and about evaluating related goal and the questionnaire was confirmed with trivial corrections.

One of the methods for calculating reliability is Cronbach's alpha coefficient, which was calculated by the help of test variance and by the help of SPSS software that was 0.92 for present research questionnaire.

\section{Results}

Fig. 1 shows demographic information extracted from questionnaires.

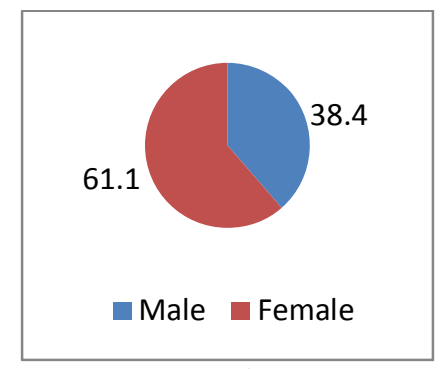

Gender

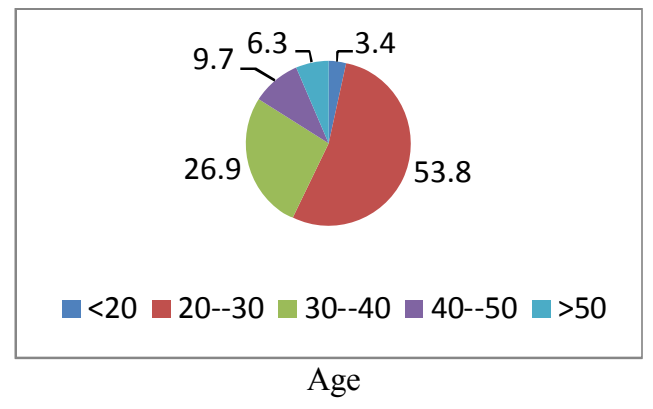

Fig. 1. Personal characteristics of the participants

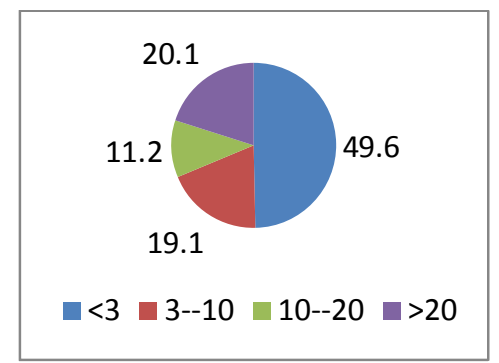

The number of online transactions during the last year

In addition, Table 1 shows details of the numbers calculated for different component of the survey. 
Table 1

Descriptive statistics of research variables

\begin{tabular}{llcc}
\hline Variable & Subscale & Mean & SD \\
\hline Traditional characteristics & Size & 4.1084 & 0.61131 \\
& Reputation & 3.9600 & 0.56371 \\
\hline Website characteristics & Perceived privacy & 4.0165 & 0.75467 \\
& Perceived security & 3.8362 & 0.69621 \\
& Perceived ease of use & 3.8729 & 0.67109 \\
\hline Trust in e-banking & Trust in e-banking & 4.1149 & 0.78462 \\
\hline Tendency to matching with e-banking & Tendency to matching with e-banking & 4.3201 & 0.62176 \\
\hline WOM advertising & WOM advertising & 3.9426 & 0.80006 \\
\hline
\end{tabular}

In order to test whether the model has an appropriate fitting, model fitting index has been used. In modeling structural equations, emphasizing on the use of Amos20 software, the three indexes of absolute fitting, adaptive and thrifty should be used. By the use of general indexes of fitting it can be answered that regardless of special reported amounts for parameters, whether in general the designated model is supported by gathered experimental data or not.

Chi-Square (CMIN) is equal to 248.959 and the level of significance is less than 0.01 , which shows a desirable result but the importance of degree of freedom (df) should not be ignored. The ratio of chisquare on degree of freedom (CMIN/df) is designed for judgment of the model. In our survey, this amount is equal to 2.621 and it is within desirable limit of 1-5. Table 2 shows other characteristics of the survey.

Table 2

Goodness of fit Indices for the model

\begin{tabular}{lllll}
\hline & fit index & value & criterion & Interpretation \\
\hline Absolute & CMIN & 248.959 & - & Good fit \\
& P-value & Less than 0.01 & Less than 0.05 & Good fit \\
& DF & 95 & 120 & Good fit \\
\hline Comparative & TLI & 0.951 & Higher than 0.9 & Good fit \\
& CFI & 0.961 & Higher than 0.9 & Good fit \\
\hline Parsimonious & PNFI & 0.743 & Higher than 0.5 & Good fit \\
& PCFI & 0.561 & Higher than 0.5 & Good fit \\
\hline Relative & CMIN/DF & 2.621 & Between 1 \& 5 & Good fit \\
& RMSEA & 0.065 & Between 0 \& 1 & Good fit \\
\hline
\end{tabular}

Now, for surveying this question that how website characteristics and traditional characteristics influence customers' trust in electronic banking and electronic commitment, the method of route analysis is applied by the use of Amos software. Table 3 demonstrates the results of our survey.

\section{Table 3}

Investigating significant differences of estimated values of parameters from zero

\begin{tabular}{lcccc}
\hline Hypothesis & $\begin{array}{c}\text { Regression } \\
\text { coefficient }\end{array}$ & $\begin{array}{c}\text { Critical } \\
\text { value }\end{array}$ & P-value & Result \\
\hline Traditional characteristics->-trust & 0.327 & 4.395 & Less than 0.01 & accepted \\
Web site characteristics ---> e-trust & 0.391 & 5.106 & Less than 0.01 & accepted \\
E-trust--->tendency to matching & 0.797 & 12.335 & Less than 0.01 & accepted \\
Tendency to matching---> WOM & 0.913 & 10.082 & Less than 0.01 & accepted \\
Size ---> e-trust & 0.597 & & Less than 0.01 & accepted \\
Reputation ---> e-trust & 0.937 & 10.460 & Less than 0.01 & accepted \\
Perceived privacy ---> e-trust & 0.800 & & Less than 0.01 & accepted \\
Perceived ease of use ---> e-trust & 0.720 & 14.529 & Less than 0.01 & accepted \\
Perceived security ---> e-trust & 0.868 & 17.483 & Less than 0.01 & accepted \\
\hline
\end{tabular}


As it is observed, all the P-value amounts are within desirable level. Fig. 2 shows details of structural equation modeling.

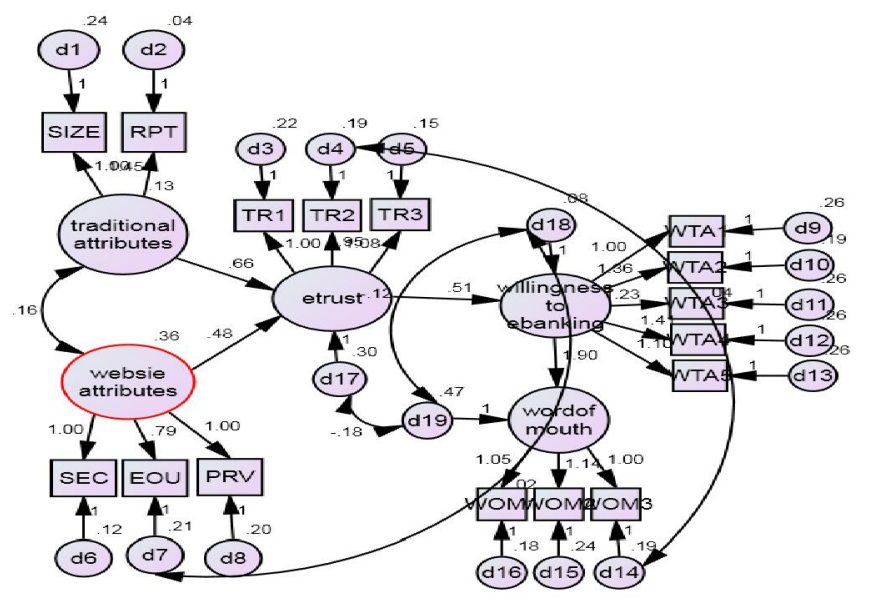

Fig. 2. The summary of structural equation modeling

In Fig. 2, RPT shows the reputation, PRV shows perceived privacy, EOU shows ease of use and SEC shows perceived security. Both online and traditional elements have nearly equal importance and none can be omitted from modern banking and management strategies. Increase of customers' trust in electronic banking increases customers' tendency to match with electronic banking, which improves positively word of mouth advertisement by the coefficient of 0.91 . Size and reputation have positive relationship with traditional characteristics and trust in electronic banking and hypothesis 2-a and 2-b are confirmed. In addition, three characteristics, perceived security, perceived ease of use and perceived privacy have direct relationship with website characteristics and trust in electronic banking that increase the intention to match with electronic banking which confirms hypothesis1-a,1-b and 1c. Therefore, bank traditional characteristics and bank website characteristics have direct relation and improve intention to match with electronic banking, so the first two main hypotheses are confirmed. Among traditional characteristics, in comparison to the size, reputation has the most effect on the relation between traditional characteristics and trust. Among website characteristics, perceived security effect on the relation of website and trust is more significant. Of course, this effect has little difference with perceived privacy. Load factors are 0.87 and 0.80 , respectively. The two factors of bank traditional characteristics and bank website characteristics have direct relation with 0.39 coefficient with trust in electronic banking. On the other side intention to matching with electronic banking with the coefficient of 0.91 increase positive word of mouth advertisement and thus the fourth main hypothesis is confirmed.

\section{Conclusions}

This study has confirmed all three main hypotheses and five secondary hypothesis of the research. Hsiao et al. (2010) surveyed backgrounds and outcomes of trust, in online products advices and concluded that perceived ability, perceived truthfulness/benevolence, perceived critical crimes and trust in a website are four important background of trust in product advice in social networks sites. In 
addition, trust in product advices can affect customers' intention to shopping from website through increase of intention to product purchasing. Ming and Shao (2010) surveyed the relationship between mobile aesthetic design and customers' trust in mobile commerce in a research as "increase of trust in mobile commerce through aesthetic". The results show that aesthetic design influences website characteristics component noticeably. Ebrahimi (2010) surveyed effective elements on forming consumers' trust in internet shop in a result. This research shows that in the absence of face to face interactions, the consumers rely on their perceptions of risks, safety protection, internet shop reputation and protecting personal sanctum. All of the stated researches confirm the results of present research and they are somehow backups for acquired results.

\section{Acknowledgment}

The authors would like to thanks the anonymous referees for constructive comments on earlier version of this paper.

\section{References}

Alexandrov, A., Lilly, B., \& Babakus, E. (2013). The effects of social-and self-motives on the intentions to share positive and negative word of mouth. Journal of the Academy of Marketing Science, 41(5), 531-546.

Bradach, J. L., \& Eccles, R. G. (1989). Price, authority, and trust: From ideal types to plural forms. Annual review of sociology, 15(1), 97-118.

Çelik, H. (2011). Influence of social norms, perceived playfulness and online shopping anxiety on customers' adoption of online retail shopping: An empirical study in the Turkish context. International Journal of Retail \& Distribution Management, 39(6), 390-413.

Chang, H. H., Jeng, D. J. F., \& Hamid, M. R. A. (2013). Conceptualising consumers' word-of-mouth behaviour intention: evidence from a university education services in Malaysia. Service Business, 7(1), 17-35.

Chellappa, R. K. (2013). Consumers' trust in electronic commerce transactions: the role of perceived privacy and perceived security. From www.bus.emory.edu/ram/papers/sec-priv.pdf.

Chung, K. H., \& Shin, J. I. (2010). The antecedents and consequents of relationship quality in internet shopping. Asia Pacific Journal of Marketing and Logistics, 22(4), 473-491.

Doney, P. M., \& Cannon, J. P. (1997). An examination of the nature of trust in buyer-seller relationships. the Journal of Marketing, 61(2), 35-51.

Eastelik, M. A. \& Lotz, S. (2010). Cognitive and institutional predictors of initial trust toward online retailer. International Journal of Retail and Distribution Management, 39(4), 234-255.

Ebrahimi, H. (2010). Factors affecting the formation of consumers' trust in online purchases. M.A thesis, University of Isfahan, Iran.

Fakut Saqieh, A. (2009). Electronic banking from theory to practice, Tehran: Taraneh Publication [In Persian].

Fang, Y., Chiu, C. M. \& Wang, T.G. (2011). Understanding customer's satisfaction and repurchase of IS success model, trust and justice. Internet Research, 21(4), 479-503.

Grabner-Krauter, S. \& Faullant, R. (2008). Consumer acceptance of internet banking : the influence of internet trust. International Journal of Bank Marketing, 26(7), 483-504.

Goodarzi, A. \& Zobeydi, H. (2008). Effects of expansion of electronic banking on the profitability of commercial banks in Iran. Iranian Journal of Economic Research, 35, 111-140.

Hsiao, K., Wang, X., Lu, H. \& Yu, H. (2010). Antecedents and consequences of trust in online product recommendations. Online Information Review, 34(6), 935-953.

Hoehle, H., Scornavacca, E. \& Huff, S. (2012). Three decades of research on consumer adaption and utilization of electronic banking channels: A literature analysis. Decision Support System, 54(1), $122-132$. 
Hwang, P., \& Burgers, W> (1997). Properties of trust: An analytical view. Organizational Behavioral and Human Decision Processes, 69(1), 67-73.

Jarvenpaa, S.L., Tractinsky, N. \& Vitale, M. (2000). Consumer trust in an internet store. Information Technology and Management, 1(1-2), 45-71.

Keaveney, S. M. (1995). Customer switching behaviour in service industries: an exploratory study. Journal of Marketing, 59(2), 71-82.

Kim, H. \& Song, J. (2010). The quality of word-of-mouth in the online shopping mall. Journal of Research in Interactive Marketing, 4(4), 376-390.

Liao, C., Liu, C. C., \& Chen, K. (2011). Examining the impact of privacy, trust and risk perceptions beyond monetary transactions: An integrated model. Electronic Commerce Research and Applications, 10(6), 702-715.

Liao, Z. \& Tow Chung, M. (2001). Internet-based e-banking and consumer attitudes: An empirical study. Information and Management Journal, 39, 283-295.

Luhmann, N. (1979). Trust and Power. John Willey and Sons, London

Mayer, R. J., Davis, J. H., Schoorman, F. D. (1995). An integrative model of organization trust. Academy of Management Review, 20, 709-734.

McCole, P., Ramsey, E., \& Williams, J. (2010). Trust considerations on attitudes towards online purchasing: The moderating effect of privacy and security concerns. Journal of Business Research, 63(9), 1018-1024.

McKnight, H. D. \& Chervany, N.L. (2002). What trust means in e-commerce customer relationships: an interdisciplinary conceptual typology. International Journal of Electronic Commerce, 6(2), 3559.

McKnight, H. D., Cummings, L. L. \& Chervany, N. L. (1998). Initial trust formation in new organizational relationships. Academy of Management Review, 23(3), 473-490.

Midha, V. (2012). Impact of consumer empowerment on online trust: An examination across gender. Decision Support System, 54(1), 198-205.

Ming, Y., \& Shao, Y. Y. (2010). Increasing trust in mobile commerce through design aesthetics. Journal Computers in Human Behavior, 26, 637-687.

Molinari, L. K., Abratt, R. \& Dion, P. (2008). Satisfaction, quality and value and effect on repurchase and positive word-of-mouth behavioral intention in B2B service context. Journal of Service Marketing, 22(5), 363-373.

Norouzi, A. (2008). Security of internet banking services and its relationship with trusted users. M.A thesis. University of Isfahan, Iran.

Palvia, P. (2009). The role of trust in e-commerce relational exchange: A unified model. Information \& Management Journal, 46, 213-220.

Pour Zarandi, M. \& Najafi, M. (2012). Examine the impact of e-banking service quality on customer satisfaction. Journal of Management, 26, 29-42.

Ratnasingham, P. (1999). Risks in low trust among trading partners in electronic commerce. Computer \& Security, 18, 587-592.

Roca, J. C., Garcia, J. J. \& Vega, J. J. (2008). The importance of perceived trust, security and privacy in online trading systems. Information Management \& Computer Security, 17(2), 96-113.

Rousseau, D. M., Sitkin, S. B., Burt, R. S. \& Camerer, C. (1998). Not so different after all: a crossdiscipline view of trust. Academy of Management Review, 23(3), 393-404.

Sotriadis, M. D. \& Zyl, C. (2013). Electronic word-of-mouth and online reviews in tourism services: the use of twitter by tourists. Electronic Commerce Research, 13, 103-124.

Weisberg, J., Teeni, D. \& Arman, L. (2011). Past purchase and intention to purchase in e-commerce. Internet Research, 21(1), 82-96.

Yap, K. B., Wong, D. H., Loh, C., \& Bak, R. (2010). Offline and online banking-where to draw the line when building trust in e-banking?. International Journal of Bank Marketing, 28(1), 27-46.

Zhou, T. (2011). An empirical examination of initial trust in mobile banking. Internet Research, 21(5), 527-540. 